\title{
Conflict Is Integral to Human-Wildlife Coexistence
}

\author{
Catherine M. Hill* \\ School of Social Sciences, Faculty of Humanities and Social Sciences, Oxford Brookes University, Oxford, United Kingdom
}

Keywords: human-wildlife conflict, human-wildlife interactions, human-wildlife coexistence, conflict narratives, conservation

\section{INTRODUCTION}

Interactions commonly labeled as "human-wildlife conflict," i.e., instances where wildlife presence and/or actions impact negatively on human interests, dominate the conservation science literature on human-wildlife interactions (Hill, 2017; König et al., 2020). However, interactions between people and wildlife are much more varied and complex than this, as exemplified in various ethnographic works including the study of people-tiger relations in the Sundarbans, West Bengal (Jalais, 2010), people-wildlife relations in Japan (Knight, 2003) and people-badger relations in the UK (Cassidy, 2019). There is increasing concern within the conservation community that the continued focus on conflict narratives risks making this the primary, or even the only, way of conceptualizing interactions between people and wildlife within this field. While obscuring opportunities for better understanding the nuances of these complex relationships this could jeopardize conservation action and outcomes (Hill and Webber, 2010; Pooley et al., 2020). One response to this is a call for a reconfiguration of the ways in which researchers study these human wildlife interactions, encouraging a shift of focus from "conflict" to "coexistence" (Frank and Glikman, 2019).

The meaning of human-wildlife coexistence is often implicit rather than explicit in much of the literature using the term (Carter and Linnell, 2016). Some authors address that deficit, but meanings assigned to the term human-wildlife coexistence vary from human-wildlife coexistence as human-wildlife co-occurrence (Harihar et al., 2013) to ideas of co-adaptation of humans and wildlife (Carter and Linnell, 2016) and human-wildlife conflict and coexistence representing two endpoints of a continuum, where "coexistence" is understood as "peaceful coexistence" (Frank, 2016). The more general emphasis appears to be on moving away from "conflict" both as a way of framing our thinking about human-wildlife interactions, and in the way we describe certain types of interaction.

The language used to describe people-wildlife encounters influences the way we interpret and imagine these experiences and relationships (Peterson et al., 2010; Hill, 2015). Arguments for revising terminology mirror an earlier debate promoting a rethink of the label "human-wildlife conflict," persuasively expounded in Peterson et al. (2010). Indeed, Pooley et al. refer to this earlier debate in their recent paper as the impetus to encourage further examination of current framing of human-wildlife interaction narratives (Pooley et al., 2020). However, the move to adopt a coexistence focus appears driven by more than just a switch away from a human-victim: animal-perpetrator framing. Instead, or additionally, the emphasis is on encouraging a shift of focus from negative aspects of human-wildlife relationships, as often represented within a conservation conflicts framing (Marchini et al., 2019) to one that acknowledges, and incorporates the idea, that human-wildlife relations are not inherently or solely negative in nature, with wildlife having significant value, and groups of people exhibiting tolerance for sharing space with wildlife. 
However, we should not be too quick to drop conflict as part of the way we understand multi-species coexistence. I propose that we should consider conflict as one aspect or even a necessary condition of human-wildlife coexistence. Additionally, we should be wary of adopting a dualistic model of "conflict" to "coexistence" or a continuum perspective because neither framework adequately represents the complex nature of human-wildlife interactions, which are multifaceted, dynamic and often grounded in time and place.

\section{CONFLICT AS A COMPONENT OF, OR NECESSARY REQUIREMENT OF, HUMAN-WILDLIFE "COEXISTENCE"}

Conflicts about wildlife are complex and nuanced, involving multiple stakeholders, whose priorities, viewpoints and agendas can clash (Madden, 2004; Redpath et al., 2013; Madden and McQuinn, 2014). The Levels of Conflict framework (Canadian Institute for Conflict Resolution, 2000), adapted by Madden and McQuinn (2014) provides a useful analytical construct for understanding the intricacies of conflicts about wildlife. Madden and McQuinn demonstrate that while conflicts about wildlife can exist solely at the "dispute" level, i.e., the bodily, tangible sign of the conflict (e.g., livestock losses to carnivores), conflicts about wildlife rarely exist only at this level. Underlying conflicts exist because of historically unsolved clashes between different human groups leading to resentment, mistrust and even disruptive or uncooperative behaviors. Furthermore, deep-rooted, or identity conflict, occurs when people feel their sense of self or group is threatened, they feel unacknowledged, disempowered, and disrespected (Madden and McQuinn, 2014). Consequently, many conflicts around wildlife are entangled within the interactions and relationships between specific human groups, and to understand these conflicts fully we need to explore the underlying issues. In any of these types of scenarios it is different human values, agendas and the interplay of power relations that are key sources of conflict between the different human stakeholders, irrespective of the human-wildlife interactions under scrutiny.

According to Lederach, an academic and practitioner in conflict transformation and peacebuilding, conflict is normal in human relationships. He argues that conflict should be viewed positively, as a marker of the need for, and as a catalyst for, change (Lederach, 2003). Moreover, instead of regarding peace as the endpoint "conflict transformation views peace as a continuously evolving and developing quality of relationship" (Lederach, 2003; pg. 20). The important point is that peace is not static or the end goal of processes adopted to address conflict between protagonists but is a dynamic reflection of the state of relationships. Human interactions and relationships with other humans are "dynamic, adapting and changing," as are human interactions with wildlife (Manfredo et al., 2020). Consequently, we should think carefully before removing the concept of "conflict" from narratives about human-wildlife interactions, or to restrict its use to situations where "peaceful" coexistence breaks down.

\section{CONFLICT AS A CATALYST FOR REFLECTION AND CHANGE IN INTERACTIONS AROUND WILDLIFE}

Where conflicts about wildlife arise, or existing conflicts are exacerbated, this can be a result of changes in local human-wildlife relations, including changing wildlife population distribution and density (Leong, 2009), changes in human and/or animal behavior (Naughton-Treves et al., 2017), and even institutional and policy changes that create social and political discord with other stakeholder groups (McLennan and Hill, 2015). Consequently, conflict should be considered a catalyst for reflection and change. For example, carnivore conflict mitigation strategies in Norway focus on reducing economic impacts (compensation) and providing technical solutions to reduce livestock predation. However, the small Norwegian wolf population is concentrated in areas with little or no livestock production. Therefore, there are relatively low rates of livestock losses in these regions yet there is substantial resistance toward wolf populations in these areas among certain rural groups, including hunters. Analysis of these conflicts about wolves reveal that these are social conflicts involving multiple stakeholder groups (Skogen and Krange, 2003). Reducing wolf predation on livestock and increased monitoring of the wolves have done little to reduce conflict narratives. Instead, these actions appear to further alienate stakeholders, including pro-wolf groups, and reinforce rural people's sense that their traditional land use and livelihoods are undervalued and are threatened by the interests of the pro-wolf lobby (Skogen, 2017). The persistence of these human-wolf conflict narratives, even in the face of considerable investment of resources into conflict mitigation signals the need for reflection and revision of approach, whereby policies and practices address more closely the concerns and priorities of non-farming stakeholders who currently feel ignored.

\section{A MUTUALLY INCOMPATIBLE OR CONTINUUM PERSPECTIVE OF HUMAN-WILDLIFE COEXISTENCE IS PROBLEMATIC}

Some authors characterize human-wildlife conflict and humanwildlife coexistence as antithetical or mutually exclusive conditions, where human-wildlife coexistence refers to a situation that is conflict-free (e.g., Crespin and Simonetti, 2020; Jordan et al., 2020). Others see conflict and coexistence as opposite ends of a spectrum. Frank proposed the "conflictcoexistence" continuum, with conflict at one end involving "extreme negative attitudes or behaviors toward a species," progressing via less extreme adverse viewpoints or actions to a point of "no action taken toward wildlife, either positive or negative." The points on this continuum are not fixed, are culturally, socially, and geographically variable, and can differ for individuals and groups over time and according to changing circumstances (Frank, 2016).

In both models the implication is that peaceful coexistence is the goal of conflict management or resolution processes. 
But given the complex and fluid nature of human-wildlife relationships, and the recognition that human-human conflicts are often, if not always, part of conflicts about wildlife, representing the relationship between conflict and coexistence as a dichotomy or continuum is problematic.

Human-wildlife relationships are multi-faceted, nuanced, and intricate, and should not be conceptualized solely with reference to types and nature of physical encounters between people and wildlife. Animals have symbolic significance and this symbolic nature can be central to understanding human-animal interactions, whether conflictual, harmonious or both. This is true in the context of conflicts around wildlife, as demonstrated by Sousa et al. (2018) in their analysis of local responses to attacks by chimpanzees in Cantanez National Park, Guinea Bissau, and Skogen (2017) in his discussion of the wolf and what it symbolizes for rural and urban residents in Norway. In the former instance chimpanzee behavior is used as a vehicle for understanding unwelcome behaviors in human neighbors; in the latter instance, the animal model is a symbol of changing states. For rural Norwegians the wolf symbolizes the decline of rural populations and rural ways of living; for urbanites it symbolizes "an authentic, wild nature" (Skogen, 2017; pg. 54). Additionally, the symbolic nature of animals is not fixed. Animals can move between categories, as illustrated by Lopez-Fernandez and Frazão-Moreira's analysis of the social construction of the Iberian lynx in Portugal, and its shift in status within rural populations from "pest" to "conservation icon" (LopezFernandez and Frazão-Moreira, 2016). Animals can even straddle categorical boundaries, for example, badgers in the UK, which are legally protected "pests" (Cassidy, 2019). Furthermore, viewing animals or interactions with them, within discrete dichotomous categories is not necessarily appropriate. Goldman et al.'s analysis of lion hunting by Maasai in Kenya and Tanzania reveals that lion killing is in response to "overlapping motivations that are simultaneously social, emotional and political" (Goldman et al., 2013; p. 490), and that adopting an explanation where lion killing by Maasai is viewed as either a cultural activity or a practical response to the threat, of livestock losses (Hazzah et al., 2009), is misleading.

As illustrated above the ways in which people interpret and regard wildlife and their actions do not necessarily fall into discrete categories. Animals can simultaneously inhabit different symbolic spaces, shift between, or even straddle, categories. Adopting a dichotomous perspective (good/bad; tolerance/intolerance; conflict/coexistence) is a persuasive approach that is appealing and conceptually easy to understand but is an overly simplified and often inaccurate representation

\section{REFERENCES}

Canadian Institute for Conflict Resolution (2000). Becoming A Third-Party Neutral: Resource Guide. Ottawa: Ridgewood Foundation for CommunityBased Conflict Resolution.

Carter, N. H., and Linnell, J. D. C. (2016). Co-adaptation is key to coexisting with large carnivores. Trends Ecol. Evol. 31, 575-578. doi: 10.1016/j.tree.2016.05.006 of human-wildlife interactions. Being able to understand, recognize and accommodate the complex and fluid nature of human-wildlife relationships needs to be part of the way we conceptualize human-wildlife coexistence.

\section{DISCUSSION}

Human-wildlife interactions, including conflicts about wildlife, are complex and nuanced. Carter and Linnell (2016, pg. 575) define human-carnivore coexistence as "a dynamic but sustainable state in which humans and large carnivores coadapt to living in shared landscapes where human interactions with carnivores are governed by effective institutions that ensure long-term carnivore population persistence, social legitimacy, and tolerable levels of risk." This framing of human-wildlife coexistence acknowledges the interplay between the biological, ecological, cultural and societal factors inherent in human-wildlife relationships in shared landscapes. Furthermore, the authors acknowledge that where large-bodied carnivores and humans share landscapes, conflicts of interest are likely to arise, either between people and wildlife, or different human-interest groups. Consequently, a permanent, "conflict-less" or "peaceful" state is likely to be unachievable. I suggest that this is not restricted to human-carnivore coexistence but is applicable to humanwildlife coexistence generally, therefore meaningful ways of conceiving human-wildlife coexistence must take this into account.

Transforming conflict into coexistence, where coexistence is the permanent or long-term removal of, or significant decline in discord between the various interest groups is unrealistic. What is important here surely is that "conflict" is not specifically inter-species conflict, i.e., between humans and their wildlife neighbors, but is conflict with others be they human or nonhuman. Furthermore, conflict can be an agent for change, so removing "conflict" from ideas of coexistence is perhaps risky. Conflict, as a state, has value, it should not automatically be viewed as negative and to be avoided but should be understood as part of the experience of multi-species coexistence, and as an indicator of, and force for, change, thereby facilitating long term co-occupancy and even perhaps "sometimes peaceful" coexistence between humans and wildlife.

\section{AUTHOR CONTRIBUTIONS}

The author confirms being the sole contributor of this work and has approved it for publication. 
Frank, B. (2016). Human-wildlife conflicts and the need to include tolerance and coexistence: an introductory comment. Soc. Nat. Res. 29, 738-743. doi: $10.1080 / 08941920.2015 .1103388$

Frank, B., and Glikman, J. (2019). "Human-wildlife conflicts and the need to include coexistence," in Human-Wildlife Interactions. Turning Conflict into Coexistence, eds B. Frank, J. A. Glikman, and S. Marchini (Cambridge: Cambridge University Press), 1-19. doi: 10.1017/978110823 5730.004

Goldman, M. J., Roque de Pinho, J., and Perry, J. (2013). Beyond ritual and economics: Maasai lion hunting and conservation politics. Oryx 47, 490-500. doi: $10.1017 /$ S0030605312000907

Harihar, A., Chanchani, P., Sharma, R. K., Vattakaven, J., Gubbi, S., Pandav, B., et al. (2013). Conflating "co-occurrence" with "coexistence." PNAS 110:E109. doi: 10.1073/pnas.1217001110

Hazzah, L., Borgerhoff, M. M., and Frank, L. G. (2009). Lions and warriors: social factors underlying declining African lion populations and the effect of incentive-based management in Kenya. Biol. Conserv. 142, 2428-2437. doi: 10.1016/j.biocon.2009.06.006

Hill, C. M. (2015). Perspectives of "conflict" at the wildlife-agriculture boundary: 10 years on. Hum. Dimens. Wildl. 20, 296-230 doi: $10.1080 / 10871209.2015 .1004143$

Hill, C. M. (2017). "Introduction. Complex problems: using a biosocial approach to understanding human-wildlife interactions," in Understanding Conflicts About Wildlife. A Biosocial Approach, eds C. M. Hill, A. D. Webber, and N. E. C. Priston (New York, NY: Berghahn), 1-14. doi: 10.2307/j. ctvw04h 12.5

Hill, C. M., and Webber, A. D. (2010). Perceptions of non-human primates in human-wildlife conflict scenarios. Am. J. Primatol. 72, 912-924. doi: $10.1002 / a j p .20845$

Jalais, A. (2010). Forest of Tigers. People, Politics and Environment in the Sundarbans. Oxford, OX: Routledge.

Jordan, N. R., Smith, B. P., Appleby, R. G., van Eeden, L., and Webster, H. S. (2020). Addressing inequality and intolerance in human-wildlife coexistence. Conserv. Biol. 34, 803-810. doi: 10.1111/cobi.13471

Knight, J. (2003). Waiting for Wolves in Japan. An Anthropological Study of People-Wildlife Relations. Oxford, OX: Oxford University Press.

König, H. J., Kiffner, C., Kramer-Schadt, S., Furst, C., Keuling, O., Ford, A. T. (2020). Human-wildlife coexistence in a changing world. Conserv. Biol. 34, 786-794. doi: 10.1111/cobi.13513

Lederach, J. P. (2003). The Little Book of Conflict Transformation. Intercourse, PA: Good Books.

Leong, K. M. (2009). The tragedy of becoming common: landscape change and perceptions of wildlife. Soc. Nat. Res. 23, 111-127. doi: $10.1080 / 08941920802438642$

Lopez-Fernandez, M., and Frazão-Moreira, A. (2016). The (In)visibility of the Iberian Lynz. From vermin to conservation emblem. Anthropol. J. Eur. Cult. 25, 25-56. doi: 10.3167/ajec.2016.250202

Madden, F. (2004). Creating coexistence between humans and wildlife: global perspectives on local efforts to address human-wildlife conflict. Hum. Dimens. Wildl. 9, 247-257. doi: 10.1080/10871200490505675

Madden, F., and McQuinn, B. F. (2014). Conservation's blind spot: the case for conflict transformation in wildlife conservation. Biol. Conserv. 178, 97-106 doi: 10.1016/j.biocon.2014.07.015
Manfredo, M. J., Teel, T. L., Don Carlos, A. W., Sullivan, L., Bright, A. D., Dietsch, A. M., et al. (2020). The changing sociocultural context of wildlife conservation. Conserv. Biol. 34, 1549-1559. doi: 10.1111/cobi.13493

Marchini, S., Ferraz, K. M. P. M. B., Zimmermann, A., Guimarães-Luiz, T., Morato, R., Correa, P. L. P., et al. (2019). "Planning for coexistence in a complex human-dominated world," in Human-Wildlife Interactions. Turning Conflict into Coexistence, eds B. Frank, J. A. Glikman, and S. Marchini (Cambridge: Cambridge University Press), 414-438. doi: 10.1017/9781108235730.022

McLennan, M. R., and Hill, C. M. (2015). "Changing agricultural practices and human-chimpanzee interactions: tobacco and sugarcane farming in and around Bulindi, Uganda," in State of the Apes: Industrial Agriculture and Ape Conservation, ed Arcus Foundation (Kalamazoo, MI: Arcus Foundation).

Naughton-Treves, L., L'Roe, J., L'Roe, A., and Treves, A. (2017). "A long-term comparison of local perceptions of crop loss to wildlife at Kibale National Park, Uganda," in Understanding Conflicts About Wildlife. A Biosocial Approach, eds C. M. Hill, A. D. Webber, and N. E. C. Priston (New York, NY: Berghahn), 127-147. doi: $10.2307 /$ j.ctvw04h12.12

Peterson, M. N., Birckhead, J. L., Leong, K., Peterson, M. J., and Peterson, T. R. (2010). Rearticulating the myth of human-wildlife conflict. Conserv. Lett. 3, 74-82. doi: 10.1111/j.1755-263X.2010.00099.x

Pooley, S., Bhatia, S., and Vasava, A. (2020). Rethinking the study of humanwildlife coexistence. Conserv. Biol. 35, 784-793. doi: 10.1111/cobi.13653

Redpath, S. M., Young, J., Evely, A., Adams, W. M., Sutherland, W. J., Whitehouse, A., et al. (2013). Understanding and managing conservation conflicts. Trends Ecol. Evol. 28, 100-109. doi: 10.1016/j.tree.2012.08.021

Skogen, K. (2017). "Unintended consequences in conservation. How conflict mitigation may raise the conflict level-the case of wolf management in Norway," in Understanding Conflicts About Wildlife. A Biosocial Approach, eds C. M. Hill, A. D. Webber, and N. E. C. Priston (New York, NY: Berghahn), 49-64. doi: 10.2307/j.ctvw04h12.8

Skogen, K., and Krange, O. (2003). A wolf at the gate: the anti-carnivore alliance and the symbolic construction of community. Sociol. Ruralis 43, 309-325. doi: 10.1111/1467-9523.00247

Sousa, J., Ainslie, A., and Hill, C. M. (2018). Sorcery and nature conservation. Environ. Conserv. 45, 90-95. doi: 10.1017/S0376892917000327

Conflict of Interest: The author declares that the research was conducted in the absence of any commercial or financial relationships that could be construed as a potential conflict of interest.

Publisher's Note: All claims expressed in this article are solely those of the authors and do not necessarily represent those of their affiliated organizations, or those of the publisher, the editors and the reviewers. Any product that may be evaluated in this article, or claim that may be made by its manufacturer, is not guaranteed or endorsed by the publisher.

Copyright (๑) 2021 Hill. This is an open-access article distributed under the terms of the Creative Commons Attribution License (CC BY). The use, distribution or reproduction in other forums is permitted, provided the original author(s) and the copyright owner(s) are credited and that the original publication in this journal is cited, in accordance with accepted academic practice. No use, distribution or reproduction is permitted which does not comply with these terms. 